\title{
A mulher e o enigma. Caminhos e descaminhos da feminilidade
}

\author{
Luana Villac*1
}

\begin{abstract}
Afinal, o que quer uma mulher? Esse artigo não se propõe a responder a essa pergunta, mas a refletir sobre as motivações que a tornam tão popular dentro e fora do campo psicanalítico. Para tanto, acompanha o percurso da noção de feminilidade esboçada por Freud ao longo de sua obra, tanto em seu aspecto conservador da moral patriarcal quanto em seu ineditismo ao localizá-la como origem do psiquismo em sua condição humana de desamparo. A imagem da menina dos contos de fada perdida na floresta é evocada para amparar e alargar a reflexão.
\end{abstract}

Palavras-chave: Feminilidade, mulher, contos de fada, desamparo

${ }^{* 1}$ Estudante do Instituto Sedes Sapientiae (São Paulo, SP, Br). 
Mero incidente

Corriqueiro

Ser mulher

A vida inteira.

Céu

\section{Mulher}

substantivo feminino (1269)

1 indivíduo do sexo feminino, considerado do ponto de vista das características biológicas, do aspecto ou forma corporal, como tipo representativo de determinada região geográfica, época etc.

$\langle\mathrm{m}$. negra $\rangle\langle\mathrm{m}$. de seios pequenos $\rangle\langle\mathrm{m}$. carioca $\rangle\langle\mathrm{m}$. das cavernas $\rangle$

1.1 aquela que tem sua fisiologia e sua vida genital percebidas como essência do ser humano feminino em sua evolução

1.1.1 na puberdade, com a chegada dos ciclos menstruais, quando ovula e pode conceber; entre menina e moça

( somente em seu primeiro mênstruo sentiu-se m., sua vital e íntima diferença >

1.1.1.1 na fase núbil, pronta para casar-se; moça, mocinha

< típico patriarca nordestino, observa as $\mathrm{m}$. de sua prole: proveitosos contratos adviriam! >

1.1.2 quando deixa de ser virgem

( tornou-se m. bem cedinho com seu primeiro namorado )

2 o ser humano feminino, considerado

2.1 em conjunto, ideal ou concretamente (e Deus criou a m. )

2.2 por sua experiência inerente e cultural

(disse-lhe, como m., que dificilmente ela ascenderia à gerência )

3 descendente do sexo feminino; filha

〈- Já nasceu? - Homem ou m.?

4 m.q. mulher-feita

( tem uma filha que já é m., vive fora do país há anos > 


\section{PRIMEIROS PASSOS}

5 ( sXIV ) companheira conjugal; esposa

( sua m. não poderá acompanhá-lo devido a compromissos profissionais >

5.1 companheira, ger. constante; a outra; amante, concubina

〈 diz a lenda que marinheiros têm uma m. em cada porto >

6 p. ext. fêmea humana como parceira sexual

(mudou de vida, deixou as noitadas e as $\mathrm{m}$. >

6.1 namorada

〈 apresentou-lhes, envaidecido, sua m. atual >

7 fig. na tradição, como indivíduo e/ou coletivamente, representação de um ser

7.1 fig. cuja principal função é cuidar da família, dos afazeres domésticos etc.

( existe a m. que sonha tornar-se 'rainha do lar' >

7.2 fig. fraco fisicamente, sem defesa; apelidado de 'o sexo frágil'

〈 o que pode a $\mathrm{m}$. contra um homem em sua fúria? >

7.2.1 fig. idealmente belo; o chamado 'belo sexo'

( vive a m. sem espelho? >

7.2.2 fig. sensível, delicado, afetivo, intuitivo

( como m., chora em todo filme romântico >

7.2.3 fig. pej. insensato, superficial, volúvel

( aquela $\mathrm{m}$. troca tanto de marido quanto de cor do cabelo >

7.2.4 fig. pej. intrigante e/ou sedutor

〈 há m. que, vaidosas, fazem das dissensões entre os pares quase que um esporte >

7.3 infrm. cuja presença censura a linguagem masculina (esp. quanto ao uso de expressões de baixo calão)

(moderou-se quando percebeu que o caixa era uma m. >

8 infrm. pessoa indeterminada por opos. a senhora e dama 1

〈 uma m. deu-lhe a informação >

8.1 p.ext. obsl. serviçal ou empregada que trabalha para alguém ou em determinada tarefa

〈 trabalhava com o conselheiro uma m. muito dedicada >

9 us. como interlocutório pessoal

〈- Então, m., qual é a solução? >

10 pej. homem efeminado, que lembra uma mulher, esp. quanto aos hábitos, gostos, trejeitos considerados tipicamente femininos

11 homem homossexual, ou que é o parceiro passivo numa relação sexual com outro homem

O Grande Dicionário Houaiss da Língua Portuguesa emprega em sua versão digital 15 definições e subdefinições para nos dizer o que significa a palavra "homem". Quando chegamos à letra $\mathrm{M}$, no verbete "mulher", esse número quase 
dobra, subindo para 27. Diante dessa disparidade, é difícil resistir ao sorriso de cumplicidade ao coro que diz serem as mulheres um enigma e quem sabe até a perguntar, uma vez mais: "Mas, afinal, o que querem as mulheres?"

Entre a mocinha indefesa, a rainha do lar, a parideira, a sedutora e a (o) parceira (o) passiva (o) que o Houaiss recolhe no caldo da cultura em busca de definições possíveis, os exemplos nos falam de um vir a ser, isto é, de tornar-se mulher: "tem uma filha que já é mulher"; "somente em seu primeiro mênstruo sentiu-se mulher"; "tornou-se mulher bem cedinho com seu primeiro namorado". Mas também nos dizem de determinações: "Já nasceu? Homem ou mulher?"; "e Deus criou a mulher"; "como mulher, chora em todo filme romântico".

Entre essas duas possibilidades de ser e estar no mundo, entre o determinismo e a potencialidade, a mulher ocupa no imaginário ocidental um lugar que torna a tarefa de Houaiss bastante ingrata: um lugar indecifrável.

Frente a esse axioma, sobre o qual a psicanálise tem procurado se posicionar desde que Freud confiou aos poetas o deciframento do enigma da feminilidade, há que se perguntar o que querem aqueles que fazem essa pergunta.

Serge André, que introduziu o artigo indefinido na pergunta de Freud, dando a um de seus livros o título $O$ que quer uma mulher? (grifo nosso), defende que o culto à mulher como mistério, bem como seu outro lado da moeda - o ódio à mulher como mistificação — só servem “(...) para alimentar o desconhecimento do que constitui a verdadeira questão da feminilidade, pois postulam, todas as duas, que a mulher é como um esconderijo que dissimularia alguma coisa" (André, 1998, p. 11).

Partindo dessa reflexão, esse trabalho se propõe a percorrer algumas das sendas pelas quais Freud caminhou, avançou — e se perdeu — ao tentar responder à pergunta que ele ajudou a tornar famosa.

\section{A feminilidade como masculinidade acidentada}

O olhar de Freud sobre o feminino e suas ramificações é do início ao fim de sua obra marcado por contradições e pontos de reticências que convidam os leitores a continuar a travessia.

Joel Birman (2001), que aceitou esse desafio, e para quem as ambiguidades e enunciados contraditórios que marcam o discurso freudiano sobre a sexualidade feminina lhe são "constitutivos e fundamentais" (p. 13), localiza esta controvertida relação, sobretudo, no eixo entre a leitura da sexualidade feminina fundada na figura do falo e na promoção da maternidade, e o conceito freudiano de feminilidade. Sobre a primeira, diz o autor: 


\section{PRIMEIROS PASSOS}

É preciso que se diga logo, sem ilusões, (que a razão psicanalítica) formulou uma leitura hierárquica da diferença sexual. A promoção incontestável da figura da maternidade no discurso psicanalítico, mediante a qual o feminino se faria mulher de maneira indiscutível, é o traço mais eloquente disso. Esta seria, sem dúvida, a marca maior do patriarcado presente no discurso freudiano. (p. 24)

Com efeito, para além da maternidade, quando a mulher se tornaria, enfim, "mulher de verdade", os destinos que Freud contempla para as mulheres se inscrevem em categorias que permanecem, a seu ver, fora do âmbito da normalidade: ser um masculino inferior na frigidez e na inibição, ou um masculino invejoso no complexo da masculinidade (Néri, apud Birman, 2002, p. 29).

Freud parte da afirmação da importância do período pré-edípico no psiquismo da menina e da descoberta subsequente que esta faz da castração para justificar o estabelecimento dessas três linhas de desenvolvimento. Para ele, ao contrário do que ocorre com o menino - cujo complexo de castração é destruído pelo complexo de Édipo - a menina é instaurada no complexo de Édipo pelo complexo de castração, quando é obrigada a abandonar sua ligação pré-edipiana com a mãe pela influência da decepção com seu clitóris e da inveja do pênis. Assim, volta-se para o pai com o fim de obter deste o que a mãe lhe recusou, isto é, o pênis. A substituição deste desejo pelo desejo de um bebê, escreve Freud, é a única saída possível para o estabelecimento da feminilidade (Freud, 1931).

É a decepção com a masculinidade imaginária, portanto, que lança a menina na posição feminina. Para Maria Rita Kehl (2007), o adjetivo enigmático que Freud confere às mulheres é tributário desta perspectiva, onde a feminilidade se constituiria a partir do que ela chama de "rendição" (p. 239). Diz a autora:

A árdua evolução em direção à feminilidade a que Freud se referia estaria ligada às vicissitudes do percurso edípico para a menina, obrigada a fazer duas renúncias ao invés de uma só (como o menino), e alimentar seus progressos antes na base de decepções do que de promessas. Só pela esperança remota de algum dia recuperar sua posição fálica através da geração de uma criança - que para o inconsciente, será sempre um filho do pai — é que a mulher freudiana aceita, enfim, a enigmática posição feminina. Enigmática, sim, inclusive para a mulher, na medida em que ela encare a feminilidade como uma rendição, um sacrifício oferecido como prova de amor ao pai e seus substitutos - portanto, uma posição constituída em nome do suposto desejo do Outro, cujo sentido escapa ao sujeito em sua alienação. (p. 239)

Birman (2001) defende que a dimensão enigmática do feminino no discurso freudiano está ligada à contraposição entre a transparência da figura do masculino 
presente em sua teoria e uma patente obscuridade da feminina. Como consequência desta "crença" - palavra bem colocada pelo autor para definir tal suposição — a figura do homem inicialmente se impõe a Freud como paradigma para a leitura da mulher, como se a transparência do masculino pudesse esclarecer a obscuridade indizível do feminino, mantendo ao mesmo tempo seu estatuto de enigma.

Birman vai mais longe, ao afirmar que esta concepção implica ainda que a feminilidade seja uma derivação da masculinidade originária e, portanto, que a masculinidade represente a perfeição, enquanto a feminilidade seria a figura da "imperfeição e da decadência". Em suas palavras:

Com isso, não apenas o sexo perfeito poderia ser mais bem conhecido e falado do que o imperfeito, como também somente pela mediação da perfeição sexual a imperfeição poderia ser conhecida e efetivamente pesquisada. A luminosidade seria definitivamente masculina, enquanto a feminilidade seria obscuridade e sombra, só podendo ser revelada pela luz lançada pela masculinidade, que a retiraria do limbo, isto é, da sua posição de enigma e de silêncio. (p. 183)

\section{A feminilidade como origem}

Em sete de julho de 1898, durante a redação de $A$ interpretação dos sonhos, Freud escreveu em carta a Fliess: "Não iniciei um só parágrafo sabendo onde ele iria terminar" (p. 319). Essa frase, tão reveladora do processo criativo do inventor da psicanálise, me faz pensar na trajetória por ele percorrida para chegar ao seu conceito final, mas nunca acabado, de feminilidade.

Se Freud, ao tratar desse tema, partiu - e foi marcado em toda sua obra de uma perspectiva imbuída de patriarcalismo, engessando a mulher em um papel condizente com a moral burguesa na qual ele estava inserido, ao mesmo tempo abriu caminhos bastante revolucionários para uma nova leitura da feminilidade, os quais talvez nem ele mesmo houvesse antecipado.

A trilha para essa renovação foi aberta na chamada virada dos anos 1920, quando Freud foi levado pelos impasses da clínica a pôr em relevo a existência de pulsões sem representação no psiquismo, chegando ao conceito de pulsão de morte. Nesse contexto, o sujeito da psicanálise passou a ser o sujeito da intensidade pulsional.

Para Birman (2001), o "caos ruidoso das forças pulsionais" (p. 236), evidenciado a partir desse momento pelo discurso freudiano, põe em evidência também o mundo da invisibilidade. Diz ele:

Enquanto invisibilidade e silêncio, isto é, enquanto ausência de logos pelo silêncio que a caracterizaria, a pulsão de morte seria muito mais que o universo articulado de representação e da linguagem. Com efeito, enquanto materialização direta da força 


\section{PRIMEIROS PASSOS}

pulsional, a pulsão de morte indicaria, com eloquência, o mundo das intensidades que permeariam a subjetividade humana... (p. 236)

Assim, a invisibilidade, enquanto pura pulsionalidade, passa a ser entendida como condição subjetiva fundamental do ser humano. Nesse novo contexto, a feminilidade, como experiência radical de castração, diz respeito ao desamparo do sujeito humano e não mais se confunde com o feminino; nem, vale dizer, com o masculino.

Em realidade, justamente por evocar o terror da castração, a feminilidade, desse ponto de vista, é uma posição contra a qual as sexualidades femininas e masculinas se organizariam. Segundo Birman (2001),

Tanto os homens quanto as mulheres teriam horror à experiência da feminilidade, justamente pela ausência do falo. Como consequência disso, existiria uma forma de recusa desta pelo terror que provocaria na subjetividade, que se organizaria pela oposição sistemática contra aquela. A ordenação das sexualidades masculina e feminina, portanto, se faria pela inscrição do falo no psiquismo, sob a forma do ser e do ter. (p. 225)

Refazendo os passos que nos trouxeram até aqui, o que se pode depreender dessa formulação é que a feminilidade, precisamente pela ausência do referencial fálico, passa a ser colocada na origem do psiquismo, sendo a ordem fálica masculina uma recusa ou oposição àquela.

Esse reposicionamento teórico, que situa a imperfeição na origem da subjetividade, é uma ruptura significativa em relação à tradição patriarcalista e aponta para novas possibilidades de pensar o sujeito em psicanálise.

Com isso, a feminilidade leva Freud de volta às sendas imperfeitas, incompletas, finitas... (a lista é longa) do ser humano.

De volta, porque é evidente que a descoberta inicial do inconsciente e seus desdobramentos teóricos, como a transformação do narcisismo primário em narcisismo secundário, a diferenciação entre eu ideal e ideal de eu e a incidência da angústia de castração já consistiam em um reconhecimento da dimensão da falta. Mas, como afirma Birman, "O falo permaneceu como uma invariante nesse discurso, como signo eloquente da perfeição e representação maior do masculino (p. 214). E foi a tematização da feminilidade que levou Freud a se distanciar desse paradigma.

\section{Um atalho pela floresta}

Antes de concluir meu caminhar neste artigo pelas questões suscitadas pelo feminino, gostaria de fazer um pequeno desvio pela floresta. Mais especificamente, pela floresta dos contos de fada. 
Os contos de fada possuem uma estrutura onde os papéis são estritamente demarcados. Quem é do mal, é do mal; quem é do bem, é do bem e, principalmente, quem é mulher, é mulher.

Ao afirmar isso, refiro-me ao fato de que, via de regra, mesmo quando tem direito à aventura, a menina dos contos de fada é sempre devolvida ao papel que lhe fora designado desde o início: o de esposa do príncipe encantado ou do rei.

Para o filósofo francês Pierre Péju (1981),

Enquanto o menino é o herói-modelo, com um caminho e referências a partir dos quais ele avança, a menina possui menos caminhos que lugares onde ela deve esperar e não se mover: espera do príncipe encantado, espera do filho por nascer, espera do rei que foi para a guerra, e nisso ela não é uma heroína. (p. 143; tradução minha)

No entanto, em paralelo a esse excesso de estrutura, onde a moldura dos contos prende as meninas, há uma desestruturação posta em cena por esses relatos tradicionais. O próprio rigor do destino tradicional da menina dá à heroína do conto mais razões para fugir àquilo que a espera e a encerra. Com isso, ela vai bem mais longe que o menino nas situações de ruptura.

Se os meninos viajam para conquistar, as meninas geralmente se põem a caminho para escapar. Seu itinerário é transversal, marginal, favorecendo a errância e o choque do inesperado. Ainda segundo Péju (1981),

O menino é geralmente dominado pela ideia de itinerário, o que supõe o modelo da linha reta como o caminho mais curto e a importância das marcas e dos rastros, enquanto a menina é preferencialmente mobilizada pela intensidade da viagem. (p. 143)

Ao se perder na floresta, o Pequeno Polegar é imediatamente possuído pelo desejo de se orientar: ele sobe nas árvores para dominar a mata e encontrar um refúgio. Com as botas de sete léguas, domina a paisagem e se impõe. Bem diferente é a fuga sem referências de Branca de Neve que quanto mais corre, mais se perde, e acaba por se entregar à floresta. Não há desejo de sair ou de dominar e ela finda por estabelecer com a floresta e com os seres que ali habitam uma relação de cumplicidade radical que não é dada aos meninos nos contos.

Péju, que rejeita uma interpretação dos contos no estilo "o que isso quer dizer", vê na floresta não um refúgio provisório, mas um signo dessa margem onde os papéis se desfazem e onde se vive no terror e na inquietude. "Branca de Neve, na floresta", ele afirma, "não possui mais um destino: ela é outra, ela se mantém na ambiguidade, em um estado dificilmente situável e nomeável” (p. 139).

É importante ressaltar que, ao falar da menina na floresta nos contos, Péju não está se referindo necessariamente às crianças do sexo feminino, mas a uma entrega à incerteza da errância que geralmente é encarnada pelas meninas nesses relatos. 


\section{PRIMEIROS PASSOS}

E esta é a razão pela qual optei por pegar esse atalho ao escrever sobre feminilidade. A imagem da menina na floresta me ajuda a entender a feminilidade originária postulada por Freud a partir da formulação do sujeito da intensidade pulsional. "Seriam as intensidades que nos destinariam à errância no mundo, sem poder contar com critérios seguros oferecidos pela representação e pela visibilidade" (p. 237), afirma Birman (2001).

Perdida, desamparada, aterrorizada, sem pontos de referência, errante: à menina na floresta, é assim que lhe é dado caminhar. Indecifrável? Eu diria incontornável.

\section{Referências}

André, S. (1998). O que quer uma mulher?. Rio de Janeiro: Zahar.

Birman, J. (2001). Gramáticas do erotismo. Rio de Janeiro: Civilização Brasileira

Birman, J. (Org.) (2002). Feminilidades. São Paulo: Contra Capa.

Freud, S. (1969). O futuro de uma ilusão, Mal-estar na civilização e outros trabalhos. In Edição Standard Brasileira das Obras Psicológicas Completas de Sigmund Freud. Rio de Janeiro: Imago. (Trabalho original publicado em 1927-1931).

Freud, S. (1969). Novas Conferências Introdutórias sobre Psicanálise e outros trabalhos. In Edição Standard Brasileira das Obras Psicológicas Completas de Sigmund Freud. Rio de Janeiro: Imago. (Trabalho original publicado em 1932-1936).

Houaiss, A. (2002). Grande Dicionário Houaiss da Lingua Portuguesa. Rio de Janeiro: Objetiva.

Kehl, M.R. (2007). Deslocamentos do feminino. Rio de Janeiro: Imago.

Masson, J.M. (1985). The Complete Letters of Sigmund Freud to Wilhelm Fliess. Cambridge, Massachusetts and London: The Belknap Press of Harvard University Press.

Péju, P. (1981). La petite fille dans La Forêt des Contes. Paris: Robert Laffont.

\section{Resumos}

(Woman and the enigma - Ways and by-ways in femininity)

So what does a woman want? This article is not intended to answer that question, but to reflect on the reasons that make the question so popular both inside and outside the psychoanalytic field. The notion of femininity expressed by Freud throughout his work is discussed here, both in its conservative aspect of patriarchal morals and its uniqueness, pinpointing it as the origin of the human psyche in its condition as helpless. 
The image of the little girl lost in the forest in fairy tales is evoked to support and broaden this reflection.

Key words: Femininity, women, fairy tales, helplessness

(La femme et l'énigme - Chemins et égarements de la féminitude)

Après tout, que veut la femme? Cet article ne vise pas à répondre à cette question, mais de réfléchir sur les raisons qui la rendent si populaire dans et hors du champ psychanalytique. Dans ce but, nous suivons le parcours de la notion de féminitude ébauchée par Freud tout au long de son ouvre, à la fois selon son aspect conservateur de la morale patriarcale et selon son caractère inédit en la plaçant à l'origine du psychique, dans sa condition humaine de détresse. L'image de la petite fille des contes de fées perdue dans la forêt est évoquée pour soutenir et élargir ce processus de réflexion.

Mots clés: Féminitude, femme, contes de fées, impuissance.

(La mujer y el enigma - Caminos y descaminos de la feminidad)

Finalmente, ¿qué quiere una mujer? Este artículo no se propone responder a esa pregunta, sino a reflexionar sobre las motivaciones que la hacen tan popular dentro $y$ fuera del campo del psicoanálisis. Para eso sigue el camino de la noción de feminidad esbozada por Freud a lo largo de su obra, tanto en su aspecto conservador de la moral patriarcal como en su singularidad al localizarla como origen de la psique en su condición humana de desamparo. La imagen de la niña de los cuentos de hadas perdida en la selva es evocada para amparar y extender la reflexión.

Palavras clave: Feminidad, mujer, cuentos de hadas, desamparo

(Die Frau und das Rätselhafte. Wege und Abwege der Weiblichkeit)

Was möchte eine Frau letztendlich? Ziel dieses Beitrages ist es nicht, diese Frage zu beantworten, sondern darüber nachzudenken, welche Gründe sie innerhalb und außerhalb des psychoanalytischen Bereichs so populär macht. Dazu wird die von Freud in seinen Werken gezeichnete Auffassung von Weiblichkeit nachvollzogen: sowohl aus ihrer konservativen Perspektive der patriarchalischen Moral, wie auch aus der Perspektive der Erstmaligkeit, als er sie als Ursprung des Psychismus in seiner menschlichen Beschaffenheit der Schutzlosigkeit definierte. Das Märchenbild des Mädchens, das im Wald herumirrt, wird hier eingesetzt, um die Reflexion zu stützen und auszuweiten.

Schlüsselwörter: Weiblichkeit, Frau, Märchen, Schutzlosigkeit 


\section{PRIMEIROS PASSOS}

Citação/Citation: Villac L. (2014, dezembro). A mulher e o enigma. Caminhos e descaminhos da feminilidade. Revista Latinoamericana de Psicopatologia Fundamental, 17(4), 925-935.

Editor do artigo/Editor: Profa. Dra. Ana Cecília Magtaz

Recebido/Received: 26.9.2014/ 9.26.2014 Aceito/Accepted: 18.10.2014/ 10.18.2014

Copyright: (C) 2009 Associação Universitária de Pesquisa em Psicopatologia Fundamental/ University Association for Research in Fundamental Psychopathology. Este é um artigo de livre acesso, que permite uso irrestrito, distribuição e reprodução em qualquer meio, desde que o autor e a fonte sejam citados / This is an open-access article, which permits unrestricted use, distribution, and reproduction in any medium, provided the original author and source are credited.

Financiamento/Funding: A autora declara não ter sido financiada ou apoiada / The author has no support or funding to report.

Conflito de interesses/Conflict of interest: A autora declara que não há conflito de interesses / The author has no conflict of interest to declare.

\section{Luana Villac}

Psicanalista; Tradutora; Estudante do curso de psicanálise do Instituto Sedes Sapientiae (São Paulo, SP).

Rua Helena Antipoff, 75 - Pompeia 05026-020 São Paulo, SP, Br

e-mail: luanavillac@yahoo.com 